\title{
Diabetes: To graft or not to graft is no longer the question
}

\author{
Paul Kurlansky, MD
}

See related article on pages 304-12.

The increased prevalence of diabetes, driven in no small measure by an epidemic of obesity, has been dramatic and largely unabated. Current estimates predict an astounding incidence between 1 in 5 and 1 in 3 adults by year $2050 .{ }^{1}$ Cardiovascular disease is the leading cause of death in the diabetic population. Because of the diffuse nature of the atherosclerotic process in the diabetic patient, multiple retrospective registry and prospective randomized trials have documented the superior long-term survival of coronary artery bypass grafting $(\mathrm{CABG})$ over interventional approaches for the diabetic patient with extensive coronary artery disease. ${ }^{2-8}$ The potential role of newer-generation drug-eluting stents in ameliorating these findings awaits further evidence. ${ }^{9,10}$

It is in this context that the study by Raza and colleagues, ${ }^{11}$ in this issue of the Journal, provides many important historical, clinical, and social insights. By accessing the wealth of data in a robust and well-maintained clinical registry of a high-volume, high-quality program and applying careful and sophisticated statistical analytics, these Cleveland Clinic researchers arrived at many notable conclusions. In their study, the percentage of patients referred for CABG has dramatically increased-likely both a reflection of increased prevalence of disease and increasing awareness of the preferential success of CABG as an optimal form of therapy. The risk profile of the diabetic patient has changed, reflecting an ever-increasing higher-risk patient, despite the notable decrease in hyperlipidemia, reflecting the widespread use of statin therapy. Although diabetic patients were at increased risk for both short- and long-term morbidity and mortality, careful propensity score matching seems to have teased out the associated comorbidities from the mere fact of diabetes itself, to suggest that the incremental impact of diabetes, independent of associated risk factors, is not discernable in the early postoperative period, but rather takes an increasing toll on late mortality. Likewise, hospital costs, although

\footnotetext{
From the Department of Surgery at Columbia University, New York, NY.

Disclosures: Author has nothing to disclose with regard to commercial support.

Received for publication May 17, 2015; accepted for publication May 18, 2015; available ahead of print June 13, 2015.

Address for reprints: Paul Kurlansky, MD, Department of Surgery at Columbia

University, Black Building 210, 650 West 168th St, New York, NY 10032

(E-mail: pk2245@cumc.columbia.edu).

J Thorac Cardiovasc Surg 2015;150:313-4

$0022-5223 / \$ 36.00$

Copyright (c) 2015 by The American Association for Thoracic Surgery

http://dx.doi.org/10.1016/j.jtcvs.2015.05.051
}

certainly higher in diabetic patients, seem to be more of a reflection of associated factors than of diabetes per se.

The alarm bells having been clearly sounded, what new

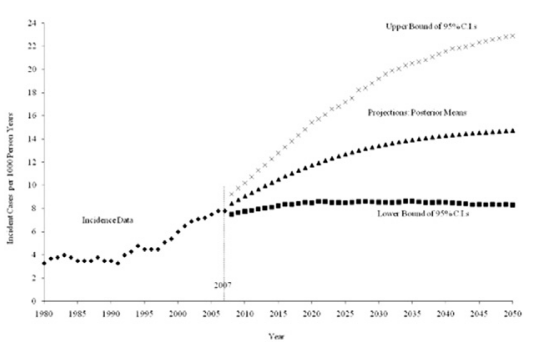
information can we glean from this study, and what questions remain to be addressed? The authors are to be commended for addressing the issue of prevention. Clearly the evidence regarding the effectiveness of lifestyle intervention in preventing diabetes is neither new nor surprising-just incredibly difficult to execute on a large scale. ${ }^{12,13}$ Similarly difficult but no less important might be the impact of smoking cessation. Although Raza and colleagues ${ }^{11}$ do not report the prevalence over time, more than half of the nondiabetic patients $(55 \%)$ and diabetic patients $(52 \%)$ were smokers. Not only is smoking a synergistic risk factor for the cardiovascular manifestations of diabetes, but smoking itself is an independent risk factor for metabolic syndrome and type 2 diabetes. ${ }^{14-16}$ Unfortunately, the dramatic decrease in adult cigarette smoking over the past half century $(42 \%$ in 1965 to $19 \%$ in 2011$)^{17}$ has not resulted in a consequent decrease in diabetes. In short, despite the promising opportunities in the realm of prevention, diabetes is likely to remain a surgical concern for the foreseeable future.

Left unanswered by the current study is the impact of diabetic severity and therapeutic approach on clinical outcome. There is increasing evidence to suggest that insulin-dependent diabetic patients have a higher risk for both short- and long-term adverse outcomes. ${ }^{18,19}$ This distinction may even help to further define the incremental benefit of CABG versus interventional approaches for the diabetic patient and therefore hopefully would be included in future study. ${ }^{20}$ Also critical to understanding the increasing risk hazard for late mortality would be the surgical therapy applied. Somewhat surprisingly from this institution, most likely because of the historical nature of the study, $33 \%$ of nondiabetic patients and $19 \%$ of diabetic patients received no internal thoracic artery (ITA), whereas only $11 \%$ of nondiabetic patients and $7.5 \%$ of diabetic patients received bilateral ITA grafts. Appropriately, propensity score matching was based on preoperative rather than operative factors, and the impact of surgical approach on the long-term outcome cannot be discerned from the data presented. Although the impact of 
single ITA grafting on long-term survival in both diabetic and nondiabetic patients is well accepted as virtual dogma, the increasing evidence documenting a long-term survival benefit for diabetic patients with bilateral versus single ITA grafting, without increased risk of deep sternal wound infection, is compelling. ${ }^{21,22}$ Last, any comprehensive analysis of costs must account for not only the upfront expenses but also the costs associated with the need for additional medical care, reintervention, longevity, and quality of life. Unfortunately, it seems that the problem will be with us for a sufficiently long time to provide us with ample opportunity to focus our future research efforts toward greater clarity in these areas.

\section{References}

1. Boyle JP, Thompson TJ, Gregg EW, Barker LE, Williamson DF. Projection of the year 2050 burden of diabetes in the US adult population: dynamic modeling of incidence, mortality, and prediabetes prevalence. Popul Health Metr. 2010;8:29.

2. Farkouh ME, Domanski M, Sleeper LA, Siami FS, Dangas G, Mack M, et al; FREEDOM Trial Investigators. Strategies for multivessel revascularization in patients with diabetes. N Engl J Med. 2012;367:2375-84.

3. Verma S, Farkouh ME, Yanagawa B, Fitchett DH, Ahsan MR, Ruel M, et al. Comparison of coronary artery bypass surgery and percutaneous coronary intervention in patients with diabetes: a meta-analysis of randomised controlled trials. Lancet Diabetes Endocrinol. 2013;1:317-28.

4. Ali JA, Franck C, Filion KB, Eisenberg MJ. Coronary artery bypass graft surgery versus percutaneous coronary intervention with first-generation drug-eluting stents: a meta-analysis of randomized controlled trials. JACC Cardiovasc Interv. 2014:7:497-506.

5. DeLuca G, Schaffer A, Verdoia M, Suryapranata H. Meta-analysis of 14 trials comparing bypass grafting vs drug-eluting stents in diabetic patients with multivessel coronary artery disease. Nutr Metab Cardiovasc Dis. 2014;24:344-54.

6. Lim JY, Deo SV, Kim WS, Altarabsheh SE, Erwin PJ, Park SJ. Drug-eluting stents versus coronary artery bypass grafting in diabetic patients with multi-vessel disease: a meta-analysis. Heart Lung Circ. 2014;23:717-25.

7. Ariyaratne TV, Ademi Z, Yap CH, Billah B, Rosenfeldt F, Yan BP, et al. Prolonged effectiveness of coronary artery bypass surgery versus drug-eluting stents in diabetics with multivessel disease: an updated systematic review and meta-analysis. Int J Cardiol. 2014;176:346-53.

8. Wu YC, Su TW, Zhang JF, Shen WF, Ning G, Kong Y. Coronary artery bypass grafting versus drug-eluting stents in patients with severe coronary artery disease and diabetes mellitus: a systematic review and meta-analysis. J Diabetes. 2015;7:192-201.

9. Bangalore S, Toklu B, Feit F. Outcomes with coronary artery bypass graft surgery versus percutaneous coronary intervention for patients with diabetes mellitus: can newer generation drug-eluting stents bridge the gap. Circ Cardiovasc Interv. 2014;7:518-25.

10. Bangalore S, Guo Y, Samadashvili Z, Blecker S, Xu J, Hannan EL. Everolimus-eluting stents or bypass surgery for multivessel coronary disease. N Engl J Med. 2015;372:1213-22.

11. Raza S, Sabik JF, Ainkaran P, Blackstone EH. Coronary artery bypass grafting in diabetics: a growing healthcare cost crisis. J Thorac Cardiovasc Surg. 2015;150: 304-12.

12. Knowler WC, Barrett-Connor E, Fowler SE, Hamman RF, Lachin JM, Walker EA, et al. Reduction in the incidence of type 2 diabetes with lifestyle intervention or metformin. N Engl J Med. 2002;346:393-403.

13. Tuomilehto J, Lindstrom J, Eriksson JG, Valle TT, Hamalainen H, IlanneParikka P, et al. Prevention of type 2 diabetes mellitus by changes in lifestyle among subjects with impaired glucose tolerance. N Engl J Med. 2001;344: 1343-50.

14. Will JC, Galuska DA, Ford ES, Mokdad A, Calle EE. Cigarette smoking and diabetes mellitus: evidence of a positive association from a large prospective cohort study. Int J Epidemiol. 2001;30:540-6.

15. US Department of Health and Human Services. The Health Consequences of Smoking-50 Years of Progress: A Report of the Surgeon General. Atlanta, GA: US Department of Health and Human Services, Centers for Disease Control and Prevention, National Center for Chronic Disease Prevention and Health Promotion, Office on Smoking and Health, 2014.

16. US Department of Health and Human Services. A Report of the Surgeon General. How Tobacco Smoke Causes Disease: What It Means to You. Atlanta, GA: US Department of Health and Human Services, Centers for Disease Control and Prevention, National Center for Chronic Disease Prevention and Health Promotion, Office on Smoking and Health, 2010.

17. Centers for Disease Control and Prevention. Trends in current cigarette smoking among high school students and adults, United States, 1965-2011. Available at: http://www.cdc.gov/tobacco/data_statistics/tables/trends/cig_smoking/. Accessed May 15, 2015.

18. Wit MA, de Mulder M, Jansen EK, Umans VA. Diabetes mellitus and its impact on long-term outcomes after coronary artery bypass surgery. Acta Diabetol. 2013;50:123-8.

19. Carson JL, Scholz PM, Chen AY, Peterson ED, Gold J, Schneider SH. Diabetes mellitus increases short-term mortality and morbidity in patients undergoing coronary artery bypass graft surgery. J Am Coll Cardiol. 2002;40:418-23.

20. Kurlansky P, Herbert M, Prince S, Mack MJ. Improved long-term survival for diabetic patients with surgical versus interventional revascularization. Ann Thorac Surg. 2015;99:1298-305.

21. Puskas JD, Sadiq A, Vassiliades TA, Kilgo PD, Lattouf OM. Bilateral internal thoracic artery grafting is associated with significantly improved long-term survival, even among diabetic patients. Ann Thorac Surg. 2012;94: 710-6.

22. Dorman MJ, Kurlansky PA, Traad EA, Galbut DL, Zucker M, Ebra G. Bilateral internal mammary artery grafting enhances survival in diabetic patients: a 30-year follow-up of propensity score-matched cohorts. Circulation. 2012; 126:2935-42. 